bodies contain not less than 35 per cent. of coagulable proteids and not more than 40 per cent. of meat bases."

It is especially noticeable among the meat juices, so called, that none shows any appreciable amount of coagulable proteids. Valentine's Meat Juice and Wyeth's Beef Juice, besides being below the standard in total solids as fluid ex. tracts, are misbranded when called meat or beef juices, as can readily be seen by comparing the results of the analyses and the standard.

Wyeth's Beef Juice is advertised as eontaining "all the albuminous principles of beef in an active and soluble form" and "in an unaltered form"...two statements that are on the face of them untrue and misleading. To say that all the albuminous principles of meat are present is to say that not only the juice of the meat but all the fiber is present, which evidently is nrt true. Then, again, to say that it is present in an unaltered form is far from the facts, for, as is stated on page 18 of the Bulletin: "It appears impracticable to prepare a true meat juice for market, as the temperature necessary for the preservation of food products in hermetically sealed packages coagulates the proteids and changes the na. ture of the product." On page 55 : "When prepared under the best possible conditions a commercial meat extract is, of necessity, in order that it may not spoil, deprived of the greater part of the coagulable proteids, which constitute the chief nutritious elements of the juice."

On examining the tables of analysis, it is seen that Wyeth's Beef Juice contains but 23 per cent. of its total proteids in a coagulable form, while the standard calls for 35 per cent., thus showing it to be no more valuable as a food product than any other so-called meat juice, the statements of the manufacturers to the contrary notwithstanding.

In the case of Valentine's Meat Juice we note a large discrepancy between the standard requirements and the results of the government analysis, for instead of the proteid matter containing 35 per cent. in the coagulable form, it contains but 1.6 per cent. These figures show; then, that Valentine's preparation contairis practically no coagulable proteids, and since the quantity of these measures the fond value of such preparations, the conclusion must be drawn that Valentine's Meat Juice has practically no value as a food and should certainly not be classed as a meat juice.

Bovinine, another widely advertised meat preparation, which, according to statements on "The Bovinine Co.'s" letter head, is "a concentrated beef juice" and "the only perfect food in the world," was analyzed and found below the standard set for meat juices, since it contains only 3.38 per cent. of coagulable proteids. Yet in spite of this discrepancy, the manufacturers of Bovinine persist in exploiting it as a food, stating it to be ". . . a concentrated easily assimilable, nitrogenous food," and in another place it is stated that Bovinine "is an ideal food." As it is deficient in coagulable proteids and thus below the requirements as a food, it is misbranded when called a food of any sort, for to quote again the Bulletin, page 55: ". . . meat extracts... must not be looked on as representing in any notable degree the fond value of the beef or other meat from which they are derived"; and, again: "They are not, however, concentrated foods, having, on the contrary, but comparatively little nutritive value."

Taken individually or as a class, meat extracts are not to be considered as foods, and should, therefore, not be advertised as such, a conclusion which the government officials have come to and voiced in the conclusion of the Bulletin as follows:

\section{VALUE AND LIMITATIONS}

"It seems to be the consensus of opinion among scientific investigators who have studied this question that the food value of these meat extracts is rather limited, and although they are a source of energy to the body they must not be looked on as representing in any notable degree the food value of the beef or other meat from which they are derived. When prepared under the best possible conditions a commercial meat extract is of necessity, in order that it may not spoil, deprived of the greater part of the coagulable proteids, which constitute the chief nutritious elements of the juice."

\section{A Needed Change in the Form of the Federal Guaranty Legend}

The federal Food and Drugs Act of 1906 provides that the retailer of an adulterated or misbranded article shall be exempt from prosecution if he can establish a guaranty signed by the manufacturer or wholesaler to the effect that the articles are not adulterated or misbranded within the meaning of the act. Hence the legend:

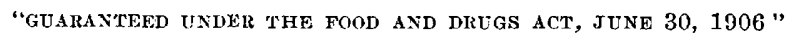

This form of guaranty was fought by the sophisticator and dishonest manufacturer until such opposition was seen to be clearly hopeless. After its inevitableness was established, the advertiser saw the commercial possibilities in the guaranty and a campaign of advertising was instituted with the one object in view of leading the public to think that "guaranteed under the Food and Drugs Act" is equivalent to a government guaranty of the purity of the product bearing the legend. This, of course, is far from the truth. To prevent the continued unscrupulous use, the wording of the guaranty clause has been changed, the modified form becoming effective Jan. 1, 1909. After that date it will read:

"Guaranteed by [NAMF of gUarantor] UNDé the Food and DRUGS ACT, JUNE 30, 1906."

To prevent loss on the part of those who have labels on which the legend appears in its older form, such labels may be used until Jan. 1, 1911. This applies, however, only to those who had their guaranty on file at Washington previous to Jan. 1, 1909.

\section{Anusol Suppositories Contain No Anusol}

Anusol, a German product widely advertised in this country, was refused recognition some two years ago by the Council on Pharmacy and Chemistry. The Pharmaceutical Journal (London) in quoting from an article by J. F. Suyver in the Apotheker-Zeitung, says:

"Anusol suppositories are put on the market with a label stating that $7.5 \mathrm{gm}$. of anusol (bismuth iodo-resorcinol-sulphonate) is contained in twelve suppositories. This statement is incorrect. 'The suppositories are found to contain neither sulphonic acid nor iodin, the sulphur present being in the form of bismuth sulphid, and the resorcin in the free state. Anusol suppositories therefore contain no 'anusol'."

\section{Correspondence}

\section{Postmortems on Tuberculous Cattle}

To the Editor:-My attention has been called to a communication from Dr. W. S. Devine of Marshalltown, Iowa, in The Journal, Dec. 19, 1908, describing a public postmortem demonstration on a cow which had been shown to be tuberculous by the tuberculin test. It might be inferred from the letter that the public postmortem demonstration on tuberculous cattle is a new means of proving to the farmer and to the milk consumer the importance of bovine tuberculosis, the great value of the tuberculin test, and the widely distributed lesions that may often be found in an apparently healthy animal.

Under the former Wisconsin law, when cattle were tested by the state anthorities and found tuberculous, they were appraised, and were slaughtered on the farm. An effort was always made to have as many of the neighboring farmers present at the postmortem examination as possible, in order that they might see for themselves the accuracy of the test and gain same idea of the importance of the disease as a menace to their herds. These semipublic demonstrations aroused the greatest interest and led to the testing of other herds in the neighworhood.

In connection with the work given to the three or four hundred farmer boys who go each winter to the State Ag. ricultural College, instruction in the application of the tu. 
berculin test has been given, followed by a demonstration of the lesions to be found in reacting animals. Such demonstrations have been given for the last ten years. They have also heen held in connection with the Farmers' Course, which is attended each winter by from 600 to 800 farmers from all parts of the state.

The interest which was aroused by these demonstrations and the results which followed in the widespread use of the test by the individual farmers, led to the giving of more public demonstrations by the state authorities in connection with the state fair, with county fairs, at farmers' institutes and at county agricultural schools. For the last five years a considerable number of such demonstrations have been given annually. The demand for them has been far in excess of the available time and funds of the state authorities.

The main phase of the question brought out in connection with these demonstrations has been the financial rather than the hygienic. The farmer was informed of the loss he was certain to incur if the disease were present in his herd and no effort were made to eradicate it. He was told of the danger of purchasing diseased animals and of feeding mixed creamery skim milk to his calves and hogs. 'He was shown apparently healthy animals, which had reacted to the test. These were slaughtered in his presence and the lesions dem. onstrated.

An effort has always been made to show animals having the disease in the early stages and also in animals having generalized tuberculosis. These demonstrations have always resulted in a large number of herds being tested. These tests have been voluniary in every case. In some of the counties in which the public demonstrations have been most numerous, from 10 to 60 per cent. of the milch cows have been tested.

At the International Congress on Tuberculosis, photographs of the public demonstrations, given in various parts of Wis consin, charts showing the number of such demonstrations given annually, and maps of the state illustrating the re sults of the demonstrations on the use of the tuberculin test, were shown in the Wisconsin exhibit. This line of work has been emphasized because the state authorities have believed that when the farmer is convinced of the economic importance of bovine tuberculosis, he will act, and the hygienic phases of the question will be solved because of his effort to protect himself. Cities then will not have to provide elaborate machinery for the enforcement of the ordinances requiring that cattle be tested, for, to save his own herd, every farmer will enforce it for himself. There is one creamery in Wisconsin, and we presume it has the unique distinction of being the only one in the United States, every patron of which has voluntarily tested his herd.

If bovine tuberculosis is ever to be eradicated in this country it will be through the cordial cooperation of the farmer with the state authorities who will teach him the value of the tuberculin test and its accuracy by such demonstrations as described by Dr. Devine.

E. G. Hastings, Madison, Wis.

College of Agriculture, University of Wisconsin.

\section{Patenting Surgical Devices}

To the Editor:-In The Jounnal, May 9, 1908, I contributed a paper entitled "Practical Cystoscopy," incidentally describing and explaining therein my latest model of examining and catheterizing cystoscope, named the "universal," which had first been introduced in 1906. In the paper I failed to mention the name of the manufacturers of the instrument, which, in the light of subsequent events, I believe to have been an unfortunate mistake on my part.

In attending the Chicago session of the Association, a month after the publication of the paper, my attention was called by a surgeon friend to several practically worthless cystoscopes being offered for sale by some of the exhibiting dealers under the name, the "Bransford Lewis" Universal Cystoscope." We examined a number of these instruments and found them to be inaccurate and lacking in every particular in the attainment of the several objects supplied by the instruments being made under my direction by the authorized makers, the Kny-Scheerer Co., 404 West Twentyseventh street, New York City.

Were I alone involved in the consequences of what must necessarily prove unfair treatment of the profession, 1 should probably have nothing to say about it; but when medical friends and correspondents tell me of having purchased and found wanting such spurious instruments, under the assurance that they were correctly and properly made, I feel that I should be doing them as well as others in the profession a material injustice in maintaining silence, aside from inviting obliquy and condemnation for myself.

In developing an intricate instrument of this sort, in determining the harmonious adjustment of its several parts, the construction and setting of its lenses, provision for irrigation, ureter-catheterization, etc; it is needless to say that numerous conferences, reviews and criticisms must be exchanged between the designer and the maker before a practical, serviceable and satisfactory product can be evolved; and it is obviously impracticable for such conferences to be carried on with several different instrument makers at the same time.

It is necessary, therefore, that one capable and conscientious maker be selected to manufacture and sell the instrument to the advantage of all parties concerned: the author of the device, on whom credit or blame must fall, according to the merit of the product; the physician or surgeon who buys and uses it-with success or failure, for the same reason; the patient on whom it is used, with benefit or injury; and finally, the legitimate manufacturer himself, who is necessarily subjected to the expenditure of much time and money, preliminary to the completion of untried plans and designs. Deviation from such a course can only bring injury, disappointment and distrust to all concerned, with one exception, the interloping, unauthorized imitator or maker of the device. Him alone does it seem to benefit, and his profit must needs be short-lived, at best.

The profession itself in its individual membership must be the greatest sufferer from interloping of this kind, and yet it makes practically no provision to protect itself.

Is this not a subject well worthy the attention of those in whose hands the destinies of our Association lie?

In addition to the specific interdiction of the Principles of Medical Ethics (Chap. II, Art. I, Sec. 8), there is widespread and deep-lying sentiment against the patenting of surgical instruments by a member of the profession. It is hardly deemed proper for him to receive monetary compensation for his talent or his pains. The product of these, in the shape of a surgical instrument or device, he must bestow freely and without reservation "for the benefit of humanity."

And yet experience does not prove that the patenting of devices redounds to the injury of humanity, or that their nonpatenting promotes humanity's interests. It is a well-established fact that the patenting of a device permits and actually leads to the cheapening of its sale price and without lowering its standard of excellence--the vastly greater number made insuring better workmanship, better materials and better output, justified by the greater commercial field, that are awaiting it.

In my opinion, from whatever standpoint we view it, the same conclusion must be reached: Failure to furnish some means of control and protection for its members by the profession brings about consequences injurious alike to the originator of an instrument, to its legitimate manufacturer, to the member of the profession who buys it, to the member who makes use of it, and to the patient on whom it is to be used, $i$. e., humanity. The only one who reaps the benefit of such insecure and unreasonable conditions is one deserving no such consideration at our hands, the irregular and not over-scrupulous maker who rushes into the field, makes and sells imitations of an instrument before its maturing and completion, even oy its author; modifies it, "improves" it according to his owr ideas; uses the author's name if he likes, or if better suited to commercial purposes he discards that name and applies either his own or some other in alliance with him-all in total disregard of the author's directions, 